\title{
The research on die structure of aluminum alloy bars for preventing the
}

\section{coarse grain}

\author{
Rurong Deng ${ }^{1, a^{*}, P e n g}$ Yun ${ }^{2, b}$, Xuemei Huang ${ }^{3, c}$ \\ ${ }^{1}$ Guangzhou Vocational College of Science and Technology,Guangzhou,510550,China \\ ${ }^{2}$ Guangzhou Vocational College of Science and Technology,Guangzhou,510550,China \\ ${ }^{3}$ Guangzhou Vocational College of Science and Technology,Guangzhou,510550,China \\ aemail:SQF6410@163.com,,email:441752102@qq.com, email:41784402@qq.com
}

Keywords: aluminum alloy bar, coarse grain, die structure, the degree of deformation, press stress Abstract. the application of aluminum alloy bars are widely. The main problems in the production process is coarse grain. Through the analysis of the characteristics of the metal in the process of extrusion forming, introduced the effect of the die structure on the degree of deformation and press stress and the effect on the coarse grain. And obtained the die structures avoiding the coarse grain showed that it is feasible in practice, it can be used for reference.

\section{Introduction}

As $\mathrm{Al}$ alloy has good corrosion resistance, can be welded and light weight, so that the application of extruded bars is becoming more and more extensive. On the one hand, it can be used as the blank or two extrusion of the structural parts. After the two extrusion, the extrusion effect of the alloy will be reduced or almost completely disappear under a certain condition, which is an important reason for the application of the extrusion bar.On the other hand, it can be used directly as a structure for the related industries or fields, but in the process of production, the biggest problem is that the bar is easy to appear the phenomenon of coarse grain ring, which seriously affect the performance of the material.There are many factors that affect the grain production. Many scholars, engineers and technicians have carried out a lot of research, but mainly concentrated on the extrusion process of aluminum alloy, chemical composition of the alloy, and the processing of homogenization. At present, the production mode of aluminum alloy bar mainly adopts the way of positive extrusion.Many studies have neglected the influence of forming process on the grain size, which is the influence of the degree of extrusion deformation and the stress on the grain size.Because of the extrusion process, the deformation degree and extrusion ratio are small, so the extrusion pressure is relatively small.From the angle of extrusion, it is easy to realize the extrusion forming.But the practice shows that the size of the metal deformation and the size of the extrusion force are also the important factors to determine the grain size, while the die structure is an important factor affecting the deformation degree and the extrusion pressure.Therefore, only from the aspects of technology, composition of the research and analysis of the factors that appear coarse grains, which is very limited, it is necessary to fully understand the factors of the coarse grain, it must consider the factors of the mold.By introducing the way of changing the structure of the die, the deformation degree and the pressure stress of metal forming can be changed, so that the mechanical properties of the bar can be avoided, and the path is provided 


\section{Die Test}

\section{Scheme Design}

Take Ø $25 \mathrm{~mm}$ bar as a test product, respectively, extruded in the extrusion machine $8 \mathrm{MN}$ and $18 \mathrm{mN}$.Design and manufacture of die 4 sets were numbered 1 to No.4, die main form as follows:

(1) die of NO.1: $8 \mathrm{MN}$, Single hole design.

(2) die of NO.2: $18 \mathrm{MN}$, Single hole design.

(3) die of NO.3: $18 \mathrm{MN}$,Double hole design.

(4) die of NO.4: $18 \mathrm{MN}$,Eccentric single hole design.

The die holes layout are shown in Figure 1, the size of each of the die holes, the guide chamber size, and the bearing belt size are all the same. And the experimental results are shown in Table 1.

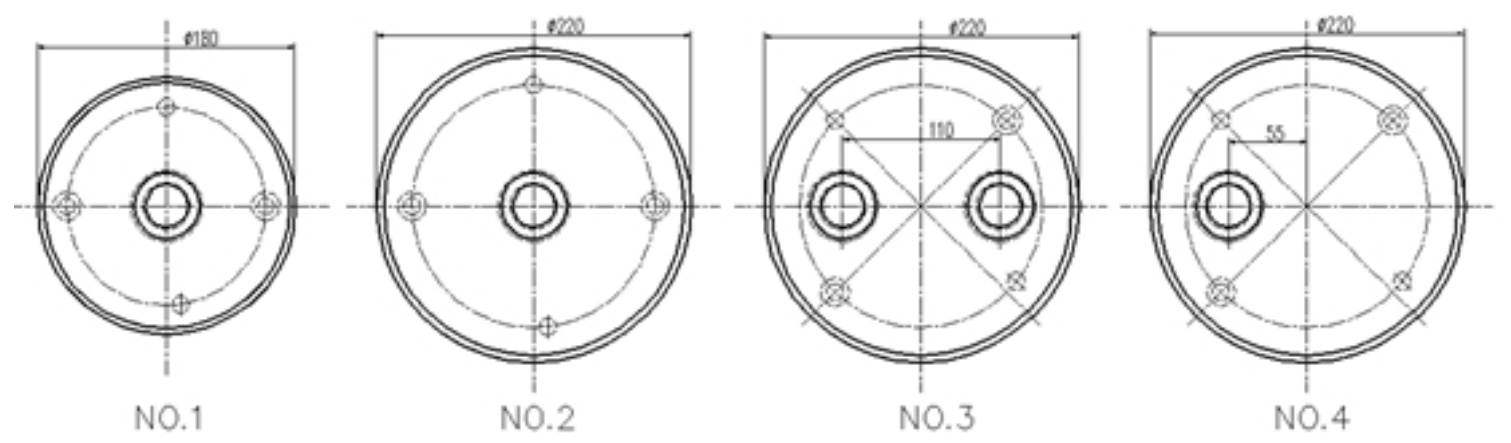

Fig.1 the signal of die hole layout for the die test

Table 1 die test and result comparison scheme

\begin{tabular}{|c|c|c|c|c|c|c|c|}
\hline $\begin{array}{l}\text { Serial } \\
\text { No. }\end{array}$ & Die No. & $\begin{array}{l}\text { Extrusion machine } \\
\text { Capability(MN) }\end{array}$ & $\begin{array}{l}\text { Bore of } \\
\text { Container } \\
(\mathrm{mm})\end{array}$ & $\begin{array}{l}\text { External } \\
\text { diameter of } \\
\text { Die }(\mathrm{mm})\end{array}$ & $\begin{array}{l}\text { Die } \\
\text { hole } \\
\text { number }\end{array}$ & $\begin{array}{l}\text { Extrusion } \\
\text { ratio }\end{array}$ & $\begin{array}{l}\text { Position of } \\
\text { die }\end{array}$ \\
\hline \multirow{2}{*}{$\begin{array}{l}\text { The first } \\
\text { group }\end{array}$} & $1 \#$ & 8 & $\begin{array}{lll}13 & 0\end{array}$ & 180 & 1 & 27 & Center \\
\hline & $2 \#$ & 18 & 185 & 220 & 1 & 55 & Center \\
\hline \multirow{2}{*}{$\begin{array}{l}\text { The } \\
\text { second } \\
\text { group }\end{array}$} & $2 \#$ & 18 & 185 & 220 & 1 & 55 & Center \\
\hline & $3 \#$ & 18 & 185 & 220 & 2 & 27.5 & Eccentric \\
\hline \multirow{2}{*}{$\begin{array}{l}\text { The third } \\
\text { group }\end{array}$} & $3 \#$ & 18 & 185 & 220 & 2 & 27.5 & Eccentric \\
\hline & $4 \#$ & 18 & 185 & 220 & 1 & 55 & Eccentric \\
\hline
\end{tabular}

\section{Structure and Result Analysis}

No. 1 and No. 2 die is currently the most frequently used a conventional structure. The die hole in the center of the die and extrusion cylinder center phase coincidence.the extrusion coefficient of No.1 die is small and the extrusion coefficient of No. 2 die is larger. Die structure is usually used in the form of a diversion chamber, for common mode (sub surface) and die pad combination, as shown in Figure 2. 

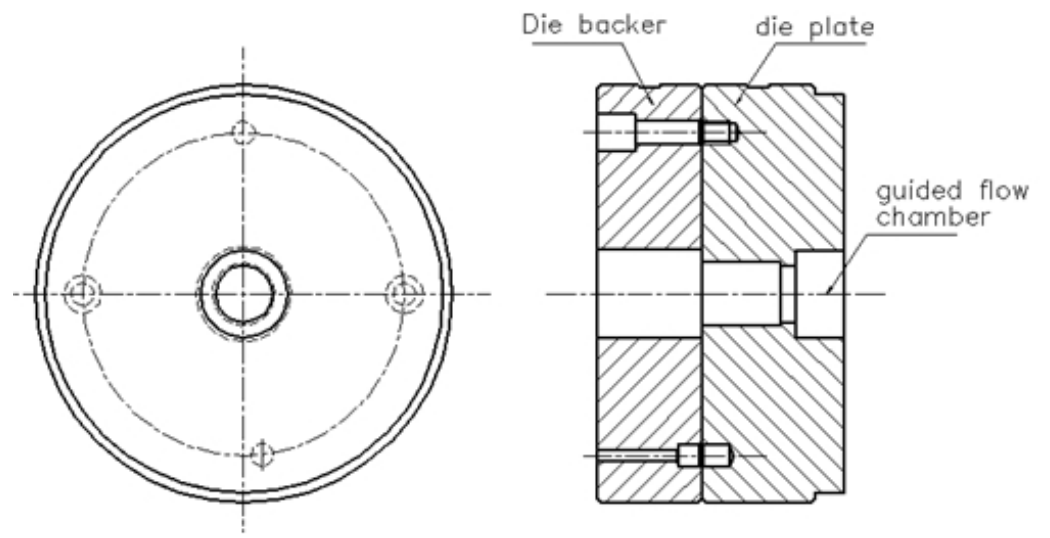

Fig. 2 the signal of traditional bars solid die

By this way, the simple die manufacturing, die hole processing can achieve very high accuracy, but when the extrusion coefficient is lower than 40 , such as No. 1 die when extrusion deformation degree of small, low extrusion pressure, the biggest shortage is profiles of grain, coarse grain phenomenon is easy to appear, the mechanical property and conductivity of the obtained lower.

The reason is that on the one hand, the extrusion coefficient is small, the deformation degree is small, the hydrostatic pressure (three-dimensional compressive stress) is small. On the other hand, the traditional die structure has only one metal pre-deformation, so the degree of pre-deformation is large. According to the experimental results, the recrystallization temperature of the metal is related to the degree of the metal deformation. The higher the degree of deformation, the higher the degree of the metal grains, This is due to the greater the degree of pre-deformation, the greater the extent of the metal grains breaking, the more defects caused by the more, the higher the organization's instability, which will start at a lower temperature. Then after crystallization of metal, generally are small and uniform equiaxed grains, such as the temperature continues to rise, after recrystallization grain to mutual annexation and grow up, therefore, resulting in coarse grain products. Of course, the extrusion coefficient and the degree of pre deformation are related, when the extrusion coefficient is smaller, the impact of the pre deformation degree is more obvious.

Therefore, in order to achieve a certain extrusion coefficient, it is necessary to choose the larger extrusion capacity of the machine or the larger the diameter of the extrusion cylinder, which will increase the cost of extrusion and the limitations of equipment conditions.

At the same time, in the process of extrusion, the joints between rods and bars are easy to be deformed or not, and when the end of each extrusion, the bar can be pulled out or the surface quality of the bar can be damaged when the bar is pulled out or the rod is pulled out.

Traditional structures are also applicable to the extrusion coefficient greater than 40 or to the surface quality and the internal microstructure of the bar is also applicable, or the extruded bars as the structural parts of the billet and the two extrusion processing, also can use this traditional structure.

(1) No.3 die for dual hole design, and No.4 die for single hole design but die hole of the eccentric set. This is to validate the same extrusion coefficient under different machine extrusion, grain size of die hole location forms under different conditions.

(2) detection method for grain size

After each mold machine extrusion, intercept length $1 \mathrm{~m}$ samples and 4 branch and grain size determination and comparison of, grain size detection method by factory usual practice, simple and practical. Soon the sample into plant oxidation plant pickling tank in about $25 \sim 30$ minutes, taken out in cleaning tank clean, you can see by the method of visual bar samples of grain size.

Table 1 in 4 sets of extrusion dies after the samples by the above method and grain size compared. Results show, No. 2 modules and No.4 die samples of grain is minimum and the most uniform, 
especially in No. 4 model of the optimum sample;And grain size of No.1 mould and No.3 die samples showed almost identical. Thus it can be seen, more extrusion coefficient is larger and the degree of deformation, the grain of the obtained products the finer and more homogeneous.From table 1 can also be seen, No.1 mould and No.3 die extrusion with similar coefficient, and No. 2 modules and No.4 die extrusion coefficient, but than No.1 mould and No.3 die extrusion coefficient nearly 1 times. Although No. 2 mode and No.4 die extrusion coefficient is the same, but No. 4 die die hole deviated from the center of a certain distance, so the deformation degree to increase. On the other hand, recorded from the field of extrusion pressure showed No.4 die extrusion pressure is the largest, followed by No. 2 die. It is also verified that the relevant information about the pressure stress of, the second phase particles broken, formed a large amount of dispersed second phase particles, increases the recrystallization temperature of the alloy, and hinder the recrystallization of grow up, so that we can get grain refinement.

\section{Improved Die Structure}

According to the results of the test and analysis of the increase of the extrusion pressure in the forming process of the three to the compressive stress and the method to increase the degree of deformation, design and manufacture of an example of the improved structure of the mold and put into production.

Die design process and analysis are as follows:

\section{Step Guide Structure}

This structure is used for the structural form of the guide plate and the model, as shown in Figure 3.

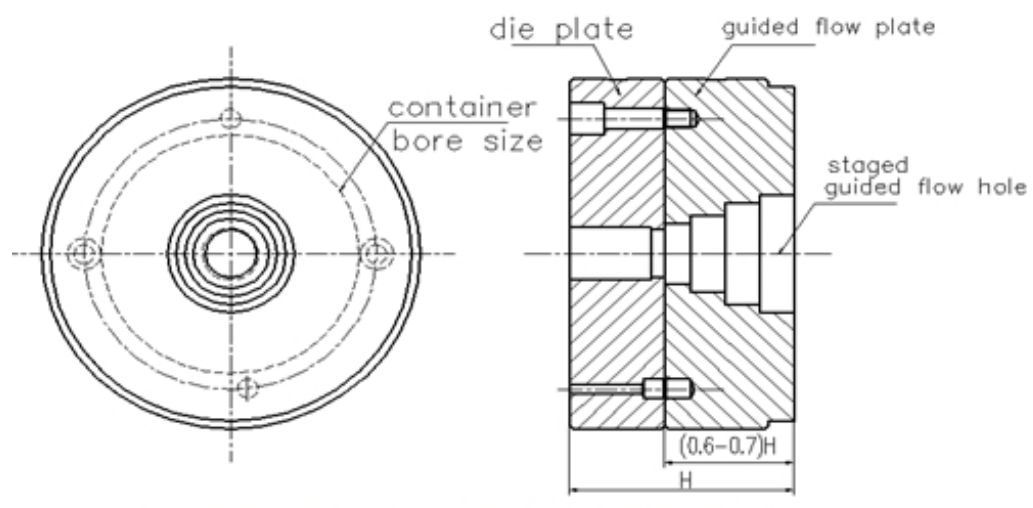

Fig. 3 the signal of solid die with staged flow guided hole

Using this structure, the diversion hole in the diversion plate or the diversion chamber with a ladder form, the thickness of the guide plate can achieve a relatively large number, the total thickness of the mold $(60 \sim 70) \%$, the ladder can be $(2 \sim 5)$, the difference between the adjacent step aperture $(4 \sim 10)$ $\mathrm{mm}$, step height $(15 \sim 25) \mathrm{mm}$, The purpose is to increase the rigidity of the extrusion forming process, increase the resistance of deformation, so that the metal after many of the pre deformation, improve the extrusion pressure, so as to improve the forming process of the hydrostatic pressure,Because, in the process of extrusion, the compressive stress can decrease the diffusion rate, the greater the pressure, the smaller the diffusion velocity, and the inhibition of the growth of [4], and then achieve the good surface quality and compact internal structure.

\section{Eccentric Die Hole Structure}

This structure is break the mold hole arrangement, the die hole arranged on the deviation from a certain location of the center of the mold on, as shown in Figure 4.

With this structure, the distance from the edge of the guide hole is greater than that of $10 \mathrm{~mm}$, which greatly increases the deformation degree and the extrusion pressure, which can greatly improve the 
hydrostatic pressure in the process of metal extrusion. At the same time, because the resistance of the metal into the die hole is greatly improved, which is equivalent to increasing the inner diameter of the tube, the extrusion coefficient is increased indirectly.Therefore, the use of this structure can avoid the generation of coarse grains, and can give full play to the potential of the extrusion equipment.

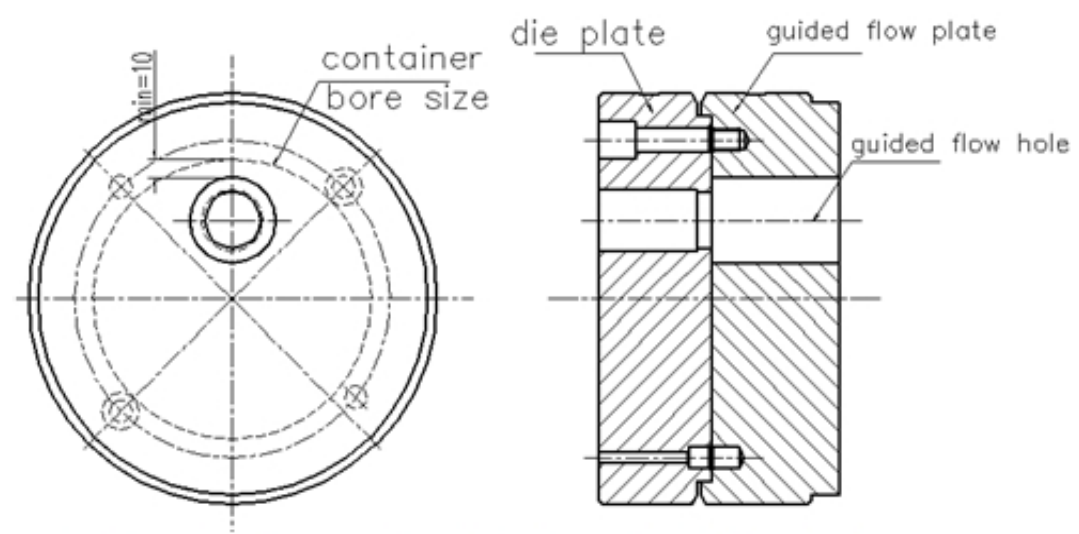

Fig.4 the signal of eccentric hole solid die with a direct flow guided hole

Using this structure, the die plate and guide plate to be carried out in the way of the end face, at the same time, the die can not be processed by precision turning or grinding process, and must be processed ed by electrical- discharge machining, but due to the die hole is round, so the difficulty is small.

\section{Step Guide Structure of Diversion Hole}

This structure has two forms:

(1)The first form is to place the hole of die in center of the die, And a $(1 \sim 2)$ - level guide chamber or a diversion chamber is added in the die, and the guide inlet on the guide plate is placed in a position which is in a position to deviate from the die center, and is in the form of an extension of the oblique approach, as shown in Figure 5.

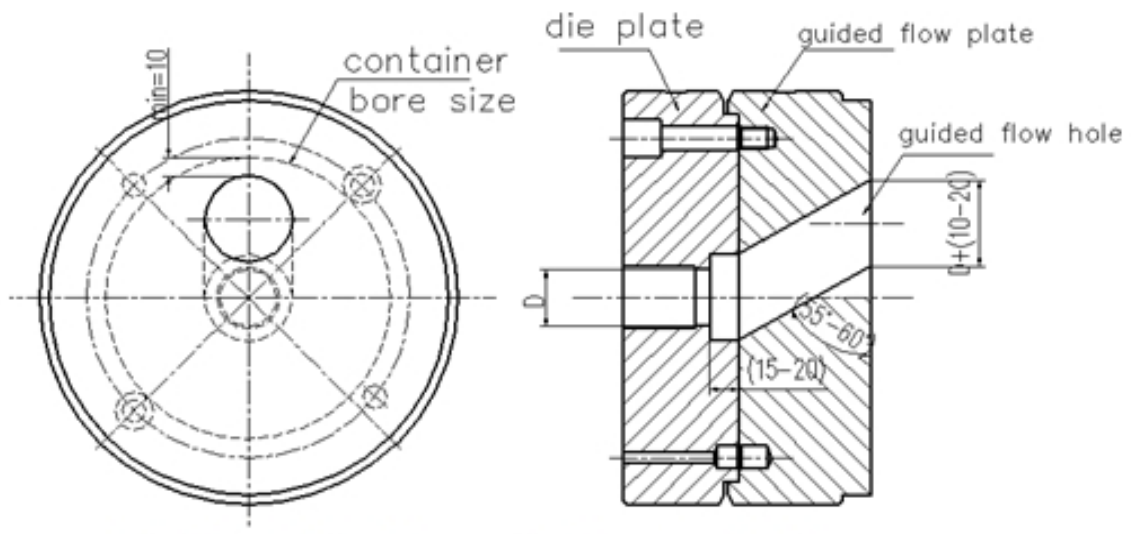

Fig.5 the signal of oblique guided hole with a die hole

With this kind of structure, the machining of die hole can be carried out by turning or grinding. It can get very high dimensional accuracy and surface quality, so it can get high quality bar products.the bars with higher requirements in the size precision and surface quality, the grain size of the bar can be used for this kind of structure, more effective.

(2)The second form is to place the die hole in a position that is off the center of the die, and the guide feeder on the guide plate is placed at the center of the die and the expansion is in the way of the oblique hole, as shown in Figure 6. 
When the two forms are used, the die plate and the guide plate should be combined in the form of end face, and the angle of the guide hole is suitable for $(55 \sim 65)$. The size of the inlet guide hole is larger than the die hole size $(10 \sim 20) \mathrm{mm}$.
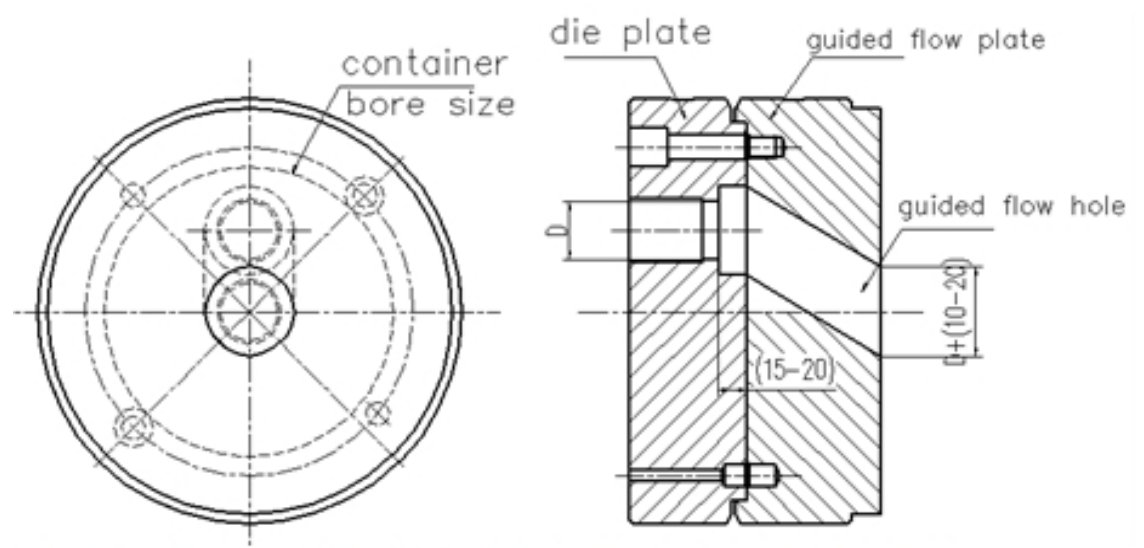

Fig.6 the signal of oblique guided flow hole with a eccentric die hole

The two types of structural form are more appropriate for the bars that the extrusion coefficient is small with the use of small extrusion machine capacity. Because, by increasing the extrusion coefficient to increase the deformation of the most direct way is to choose the larger size of the extrusion machine, but this will greatly increase the size of the mold and extrusion process energy consumption, therefore, the increase in the size of the pursuit of extrusion machine is not realistic.

\section{Result Analysis}

According to the die test of improved structure of extrusion products for sampling, detection of grain, the results show that,the grain size can be obtained through improved die and grain size is similar to the die test No.4, small and uniform.

\section{Conclusions}

According to the experimental data of the die and the results of the improved die extrusion production, this conclusion can be drawn, To improve the mechanical properties and surface quality of bar, avoid the phenomenon of coarse grain, On the basis of the research and improvement of the alloy composition, the process of metal deformation is studied, which is based on the principle of metal forming.The process of metal deformation is studied,Breaking the concept of die design, changing the structure of the mold, will be more effective to reduce or avoid the production of coarse grains, so as to improve the surface quality and mechanical properties of the bar products. In fact, the practice has shown that the effect of the improved die in the production is good.

\section{References:}

[1] Ding-wen Chen,Fei-qing Li, et al,Effect of chemical composition and homogenization treatment on the coarse grain ring of 6061 aluminum alloy rods[J].Light alloy fabrication technology,2014(02): $47 \sim 48$ In Chinese

[2]Yong-ping Feng ,Reverse extrusion process of 6061 aluminum alloy industry[J].World Non ferrous Metal,2012(02):35 37 In Chinese [3]Ru-rong Deng,Lei Zeng, The design of flow-guided die in large solid section [J],Light alloy fabrication technology,2014(11): 29 31 In Chinese 
[4]Jian-xin Xie , Jing-an Liu ,Metal extrusion theory and technology[M].Metallurgical Industry Press, Beijing,2001:28 31,68 69 In Chinese

[5]Zu-tang Wang,Xin-quan Zhang. Research on the design technology of the flow guided die for aluminum profile extrusion die[J],Light alloy fabrication technology, 1992(01): 38 42In Chinese [6] Jing-an Liu .Aluminium alloy extrusion die design, manufacture, use and maintenance. M],Metallurgical Industry Press, Beijing, 1999:159 167 In Chinese

[7]Ru-rong Deng. To determine the key parameters of aluminum extrusion die design by shunt[J],Light alloy fabrication technology,2002,30(2): $23 \sim 24$ In Chinese

[8]Ru-rong Deng.A design method of integral split mode of aluminum profile[J],Light alloy fabrication technology, 1998(04):28 29 In Chinese 